\title{
Crystal Structure, Hirshfeld Surface Analysis and Biological Activities of trans-Dipyridinebis (3-Acetyl-2-Oxo-2H-Chromen-4-Olato)Cobalt(II)
}

\section{Linda Bejaoui, ${ }_{1}^{1}$ Jan Rohlíček, ${ }^{2}$ Vaclav Eigner, ${ }^{2}$ Amel Ismail, ${ }^{3}$ Monia El Bour ${ }^{3}$ and Rached Ben Hassen ${ }^{1, *}$}

${ }^{1}$ Laboratoire des Matériaux et de l'Environnement pour le Développement Durable, LR18ES10, Université de Tunis El Manar, 9, Avenue Dr. Zoheir Safi, 1006 Tunis, Tunisie.

${ }^{2}$ Institute of Physics AS CR, v.v.i., Na Slovance 2, 18221 Prague 8, Czech Republic.

${ }^{3}$ National Institute of Marine Sciences and Technologies (INSTM), Salammbô, Tunisia.

*Corresponding author: E-mail: rached.benhassen@issbat.utm.tn

Received: 01-28-2019

\begin{abstract}
The novel cobalt(II) complex, trans-dipyridinebis(3-acetyl-2-oxo-2H-chromen-4-olato)cobalt(II), was synthesized in ethanol. The coordination sphere of the cobalt cation was elucidated using single-crystal X-ray diffraction analysis and spectroscopic techniques (FT-IR, UV-Visible and fluorescence). Hirshfeld surface analysis indicates that hydrogen bond interactions, such as $\mathrm{C}-\mathrm{H}$... O hydrogen bonding between the oxygen of lactone group and the pyridine appear as a primary interaction between the complex's molecules. The presence of $\pi-\pi$ stacking was evident by the shape index and curvature. Analysis of 2D fingerprint plots confirm that intermolecular $\mathrm{H} \cdots \mathrm{H}, \mathrm{C} \cdots \mathrm{H}$ and $\mathrm{H} \cdots \mathrm{O}$ interactions are well dominated and are in complement to the Hirshfeld surface. The metal-ligand coordination strongly influences the fluorescence intensity (the fluorescence quenching) and the offset of the emission wavelength. The metal complex was monitored for antimicrobial activity using the disk diffusion method and showed significant activity compared to the coumarin ligand.
\end{abstract}

Keywords: Coumarin; cobalt Complex; fluorescence quenching; hirshfeld surfaces; antimicrobial activity

\section{Introduction}

In recent decades, the new coumarin derivatives have received increased attention due of their important biological activities. ${ }^{1}$ Coumarins exhibit biochemical and physical properties. So, they are used as improver's agents in cosmetics products, ${ }^{2}$ fluorescent probes, ${ }^{3}$ and indicators for biological research and as medicaments, ${ }^{4}$ for the treatment of various clinical conditions. ${ }^{5}$ Research has also demonstrated the selective cytotoxicity of coumarins for tumor cells as well as their influence on the regulation of immune response, cell growth and differentiation. ${ }^{6,7}$ The physical, pharmacological and therapeutic properties of coumarins are adjusted by the substitution of a heterocyclic moiety as a substituent or as a fused component in the coumarin skeleton. ${ }^{8}$

The investigations of metal-based drugs have become an interesting subject for bioinorganic chemists. ${ }^{9,10}$ They are used as therapeutic agents for the treatment of different diseases. ${ }^{11-14}$ The scientific research in this field has proven that the binding of a drug to a metal increases its activity. In some cases, the complex has an even more interesting activity than the parent compound. ${ }^{15,16}$ In particular, several metal-coumarin complexes have also been prepared and some show a biological activity superior to that of coumarin itself. ${ }^{17,18}$

Cobalt complexes have attracted the attention in the medical field because cobalt is an essential trace element in all animals. It is mainly present as vitamin $\mathrm{B}_{12}$ which plays an important role in many biological processes. Thus, cobalt may be less toxic to the human body than other metals. ${ }^{19,20}$

New studies are based on the investment of protocols for the synthesis of new coumarin derivatives prepared from 3-acetyl-4-hydroxycoumarin, in the form of complexes, ${ }^{21}$ chalcones, ${ }^{22,23}$ aminocoumarines, ${ }^{24}$ Schiff bases, ${ }^{25,26}$ and their complexes. ${ }^{15,26}$ We always try to highlight them through structural studies, physical properties and 
biological evaluation. In this context, we continue our studies on the synthesis of new $\mathrm{Co}(\mathrm{II})$ complexes from 3-acetyl-4-hydroxycoumarin and we succeeded to prepare trans-dipyridinebis(3-acetyl-2-oxo-2H-chromen-4-olato) cobalt(II), a new complex which was characterized by spectroscopic techniques such as FT-IR, UV-Visible and fluorescence. Its three-dimensional structure is determined by single-crystal X-ray diffraction. Characterization and quantification of its intermolecular interactions are performed by Hirshfeld surface analysis. This new complex was evaluated by its antioxidant and antimicrobial activities.

\section{Experimental}

\section{1. Analyses and Instrumentation}

All analytical grade chemicals and solvent were commercially available purchased and used as received without further purification. The starting organic compound 3-acetyl-4-hydroxycoumarin was prepared as previously described. ${ }^{27}$ The IR spectra of ligand and its metal complex were recorded on a Bruker FT-IR spectrophotometer Tensor 27 by $\mathrm{KBr}$ pellet technique in the range $4000-400 \mathrm{~cm}^{-1}$. The electronic absorption spectra were recorded on double beam UVD-3500 UV-Vis spectrometer in ethanol and dimethylsulfoxide (DMSO) in the region 200-900 $\mathrm{nm}$. The fluorescence study of the complex was recorded on a SHIMADZU RF-5301PC spectrophotometer. Solutions of different concentrations $\left(c_{1}=0.6 \cdot 10^{-3} \mathrm{~mol} / \mathrm{L}, c_{2}=0.7\right.$. $10^{-4} \mathrm{~mol} / \mathrm{L}, c_{3}=1.6 \cdot 10^{-5} \mathrm{~mol} / \mathrm{L}, c_{4}=0.26 \cdot 10^{-5} \mathrm{~mol} / \mathrm{L}, c_{5}$ $=0.4 \cdot 10^{-6} \mathrm{~mol} / \mathrm{L}$ ) were prepared in DMSO and the experiments were carried out at room temperature.

\section{2. Synthesis and Crystallization}

Hot ethanolic solution of ligand 3-acetyl-4-hydroxycoumarin $(0.50 \mathrm{mmol}, 0.102 \mathrm{~g})$ was added to previously heated aqueous solution of cobalt(II) acetate tetrahydrate $\mathrm{Co}(\mathrm{OAc})_{2} \cdot 4 \mathrm{H}_{2} \mathrm{O}(0.25 \mathrm{mmol}, 0.062 \mathrm{~g})$. The mixture was heated for a few minutes, and then the pyridine $(0.5 \mathrm{mmol})$ was added to the solution. The reaction was refluxed at $70^{\circ}$ $\mathrm{C}$ for $1 \mathrm{~h}$ and then cooled down to room temperature (Scheme 1). After cooling, a purple powder was settled down and the precipitate was filtered off, washed several times with ethanol. Yield: $0.18 \mathrm{~g}$, 59\%. The successive recrystallization from ethanol produces transparent purple-color crystals of shape and size suitable for single-crystal X-ray diffraction with a decomposition temperature $\mathrm{T}_{\text {decomp }}>643 \mathrm{~K}$. FT-IR $\left(\left(v \max (\mathrm{KBr}, 4000-400) / \mathrm{cm}^{-1}\right)\right.$ : $3065(\mathrm{C}-\mathrm{H}$, aromatic), $1613(\mathrm{C}=\mathrm{O}$, ketone), $473 \mathrm{Co}-\mathrm{O}$ (coumarin), $430 \mathrm{Co}-\mathrm{N}$ (pyridine).

The purity of the sample was also checked by the $\mathrm{X}$-ray powder diffraction analysis. When the crystal structure was solved from the single crystal, the simple comparison of the measured with calculated powder diffraction pattern was made. It confirmed the phase purity of the synthesized sample.

\section{3. X-Ray Diffraction}

The single-crystal X-ray diffraction data were collected on a Supernova Atlas S2 CCD diffractometer with mirror-monochromated $\mathrm{Cu}-\mathrm{Ka}$ radiation at $120 \mathrm{~K}$. CrysAlis PRO software was used for data reduction and correction of absorption. ${ }^{28}$ The crystal data, the data collection and the details of the structure are summarized in Table 1. The structure was solved by the direct method using $\mathrm{Su}-$ perflip software, ${ }^{29}$ and was refined by least-squares calculations on $F^{2}$ with Jana2006. ${ }^{30}$ All hydrogen atoms present in the structure model were discernible in difference Fourier maps and could be refined to reasonable geometry. According to common practice, $\mathrm{H}$ atoms bonded to $\mathrm{C}$ were kept in ideal positions with $\mathrm{C}-\mathrm{H}$ bond equals to 0.96 $\AA$ A. and with $U_{\text {iso }}(\mathrm{H})=1.2 U_{\text {eq }}$. All non-hydrogen atoms were refined using harmonic refinement. The molecular and packing diagrams of new complex were generated using the software DIAMOND Version $3 .^{31}$ The ORTEP of the molecule with thermal ellipsoids was also generated. ${ }^{32}$

Table 1. Crystallographic details and structure refinement of complex

\begin{tabular}{ll}
\hline Chemical formula & $\mathrm{C}_{32} \mathrm{H}_{24} \mathrm{CoN}_{2} \mathrm{O}_{8}$ \\
$M_{\mathrm{r}}$ & 623.46 \\
Crystal system, space group & Monoclinic, $C 2 / c$ \\
$T(\mathrm{~K})$ & 120 \\
$a, b, c(\AA)$ & $16.1109(3)$, \\
$14.4864(3), 11.4281(3)$ & \\
$\beta\left({ }^{\circ}\right)$ & $98.3873(18)$ \\
$V\left(\AA^{3}\right)$ & $2638.67(10)$ \\
$Z$ & 4 \\
No. of measured, independent and & $20921,2679,2509$ \\
observed $[I>3 \sigma(I)]$ reflections & \\
$R_{\text {int }}$ & 0.028 \\
$R\left[F^{2}>3 \sigma\left(F^{2}\right)\right], w R\left(F^{2}\right), S$ & $0.026,0.083,1.15$ \\
No. of parameters & 197 \\
$\Delta \rho_{\text {max }}, \Delta \rho_{\text {min }}\left(\mathrm{e} \AA^{-3}\right)$ & $0.29,-0.21$ \\
$C C D C$ number & 1891314 \\
\hline
\end{tabular}

\section{4. Antimicrobial Assay}

The antibacterial test was carried out by using standard paper disc method according to Ismail et al. 2010, ${ }^{33}$ with slight modification. Briefly, $2 \mathrm{mg}$ of each crude extract dissolved in $1 \mathrm{~mL}$ of sterile dimethyl sulfoxide (DMSO) was applied to sterile filter paper discs $(6 \mathrm{~mm})$. Then, discs were placed on tryptic soy agar (TSA, BIO RAD) plates, which were inoculated with $18 \mathrm{~h}$ cultured of the tested pathogen $\left(10^{6}\right.$ bacteria $\left./ \mathrm{mL}\right)$ in tryptic soy broth (TSB, BIO RAD). As negative control, a disc loaded with DMSO was simultaneously prepared. Plates were incubated overnight at $30^{\circ} \mathrm{C}$. After $24 \mathrm{~h}$ incubation, inhibition 
diameter was measured in $\mathrm{mm}$. All assays were carried out in triplicate.

Bacterial type strains (8 strains) used for the antimicrobial activity evaluation of chemical compounds were: Escherichia coli ATCC 25922, Pseudomonas fluorescens (Danish Institute for Fisheries Research, Denmark), Pseudomonas aeruginosa ATCC 27853, Salmonella typhimurium C52 (Laboratoire Hydrobiologie Marine et Continentale, Université de Montpellier II, France), Staphylococcus aureus ATCC 25923, Vibrio anguillarum ATCC 12964T, Vibrio alginolyticus ATCC $17749 \mathrm{~T}$ and the yeast Candida albicans ATCC 10231.

\section{Results and Discussion}

Co(II) complex, trans-dipyridinebis(3-acetyl-2-oxo$2 \mathrm{H}$-chromen-4-olato)cobalt(II), was obtained by mixing 3-acetyl-4-hydroxycoumarin with $\mathrm{Co}(\mathrm{OAc})_{2} \cdot \mathbf{4} \mathbf{H}_{2} \mathrm{O}$ and pyridine (py) in 2:1:2 ration in absolute ethanol.

\section{1. Infrared Spectra}

The comparison of the infrared absorption spectrum of the complex (Fig. 1) with that of the ligand shows the absence of frequency of the stretching vibration $v(\mathrm{OH})$ which appears around $3435 \mathrm{~cm}^{-1}$ in the spectrum of the uncoordinated coumarin ligand. This indicates that the carbonyl groups of the ligand were deprotonated during coordination with the cobalt(II) cations. The band around $1613 \mathrm{~cm}^{-1}$ is less intense and less wide compared to the analogous band in the coumarin ligand spectrum, this band corresponds to the lactone-carbonyl fragment which is a superposition of two stretching bands of the conjugated $\mathrm{C}=\mathrm{C}$ and $\mathrm{C}=\mathrm{O}$. A decrease in the frequency of the stretch band of the $\mathrm{C}=\mathrm{O}$ acetyl group is observed with respect to the starting coumarin ligand which is may be caused by the engagement of this group in the coordination sphere of cobalt(II) cation. The low frequency region shows the appearance of new low intensity bands in the spectrum of the cobalt complex at frequencies $473 \mathrm{~cm}^{-1}$ and $430 \mathrm{~cm}^{-1}$, attributed to the vibration of the bonds $\mathrm{Co}-\mathrm{O}$ (coumarin) and $\mathrm{Co}-\mathrm{N}$ (pyridine).

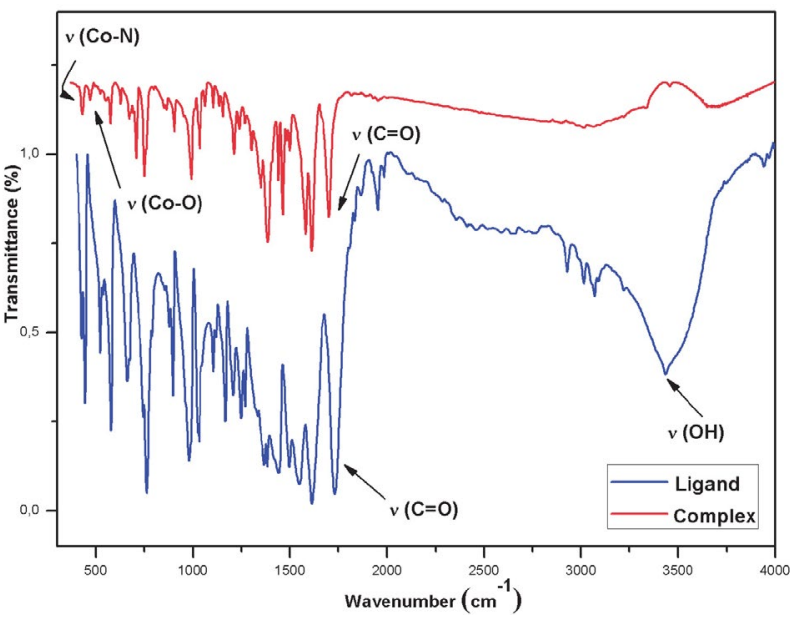

Figure 1. Comparison of the two IR spectra of the complex and ligand.

\section{2. UV-Visible Spectra}

The UV-Vis spectra of the cobalt(II) complex were recorded at different concentrations in DMSO in Figure 2 (a). For high concentrations, these spectra display a large absorption band between $440 \mathrm{~nm}$ and $610 \mathrm{~nm}$ with maxi$\mathrm{ma}$ at $509 \mathrm{~nm}$, this corresponds to the electronic transition $d \rightarrow d^{*}$. The position of the maximum is compatible with the octahedral configurations of cobalt(II) complexes. ${ }^{34} \mathrm{We}$ also observed that the progressive decrease in the concentration of the complex is accompanied by a hypsochromic displacement in the low wavelength range of the absorption bands located between $270 \mathrm{~nm}$ and $350 \mathrm{~nm}$, which are attributed to the $\pi \rightarrow \pi^{*}$ electronic transition of coumarin as well as hypochromic effect on the intensity of absorption

The electron absorption spectra of the complex in different solvents with different polarities ((DMSO) and ethanol) in order to examine the influence of the surrounding environment on the spectroscopic properties of the complex are presented in Fig. 2 (b). The absorption spectrum of the complex in DMSO solvent shows a redshift of the absorption maximum of the $\pi \rightarrow \pi^{*}$ transition with $\lambda_{\max }=314 \mathrm{~nm}$ compared to the spectrum recorded in ethanol $\left(\lambda_{\max }=302 \mathrm{~nm}\right)$ and a hyperchromic effect. This is manifested by the dipole interaction between the complex

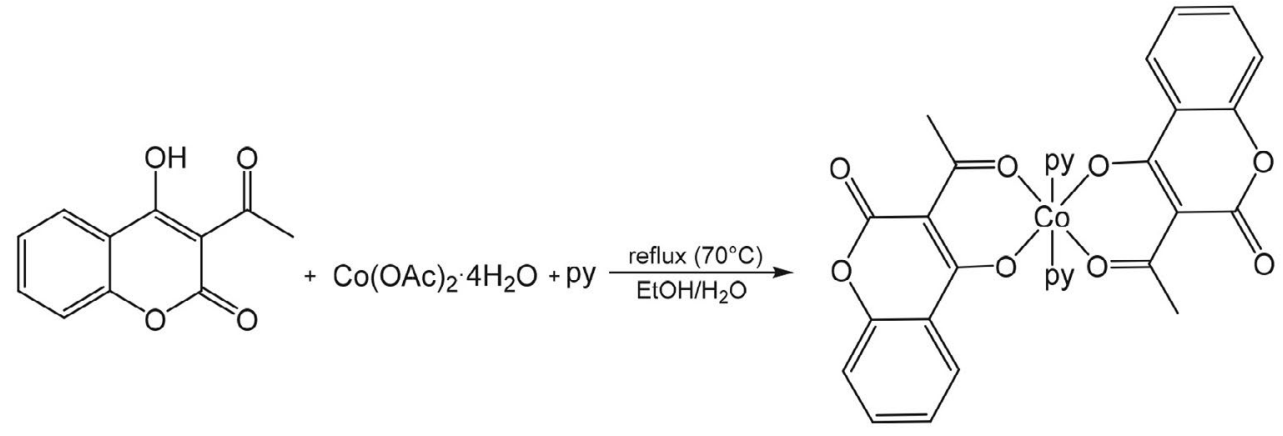

Scheme 1: Synthesis of trans-dipyridinebis(3-acetyl-2-oxo-2H-chromen-4-olato)cobalt(II). 

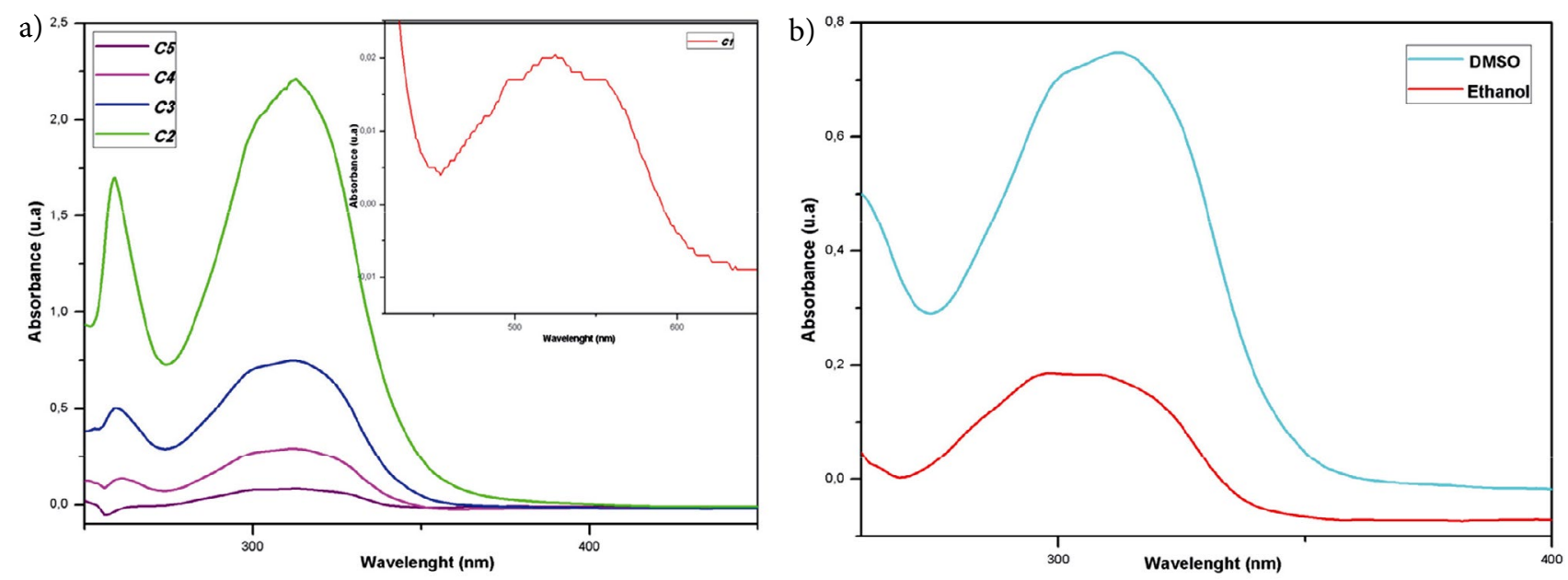

Figure 2. (a) Absorption spectra of complex recorded in DMSO at different concentrations $c_{2}=0.7 \cdot 10^{-4} \mathrm{M}, c_{3}=1.6 \cdot 10^{-5} \mathrm{M}, c_{4}=0.26 \cdot 10^{-5} \mathrm{M}$ and $c_{5}=0.4 \cdot 10^{-6} \mathrm{M}$. The inset shows the spectrum at $c_{1}=0.6 \cdot 10^{-3} \mathrm{M}$. (b) UV-Visible spectra of complex Co(II) at different solvents (EtOH and DMSO) at $1.6 \cdot 10^{-5} \mathrm{M}$ concentration.

molecules and the surrounding molecules of the polar solvent, which causes a decrease of the energy difference of the HOMO-LUMO of electronic transition $\pi \rightarrow \pi^{*}$ and consequently an increase of the wavelength. This result is evident when comparing the spectra of the complex studied in ethanol and DMSO.

\section{3. Fluorescence Spectra}

The analysis of the fluorescence spectrum of the complex in DMSO at concentration of $10^{-5} \mathrm{M}$ shows that the excitation peak of its possible fluorescent center is almost identical to its corresponding absorption band (recorded under the same conditions) and that the emission spectrum is approximately an inverted image of the absorption spectrum with a slight red shift (Fig. 3). The wavelength interval between the peak position of the absorption spectrum and the peak of the fluorescence spectrum of the same electron transition $\pi \rightarrow \pi^{*}$ is called the Stokes shift. Indeed, the probability that an electron re-

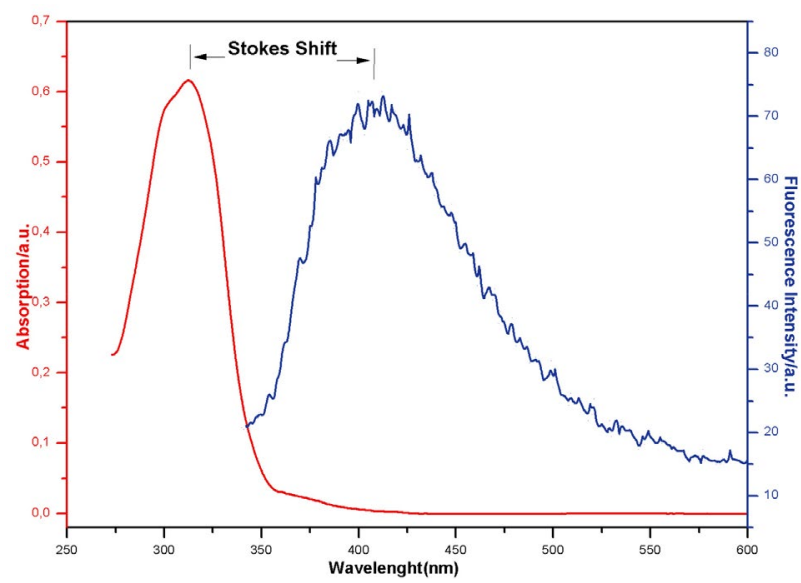

Figure 3. The absorption and emission spectra of the complex in DMSO at $10^{-5} \mathrm{M}$. turns to a particular vibrational energy level in the ground state is similar to the probability that this electron is in the ground state before excitation. That is, the same electronic transitions are the most favorable for absorption and emission. This concept is known as the mirror image rule.

The analysis of the emission spectra of the complex at different concentrations (Fig. 4) in the DMSO for a 330 $\mathrm{nm}$ excitation corresponding to the $\pi \rightarrow \pi^{*}$ transition shows a broad band of fluorescence in the blue-green region with a maximum emission at about $416 \mathrm{~nm}$. The increase in the concentration of the complex solution resulted in a significant decrease in the intensity of photoluminescence and a hypochromic shift towards the low wavelengths. This decrease is due to the solvation phenomenon, to the interaction between the solvent and the solute, as well as to the coordination effect of the co-

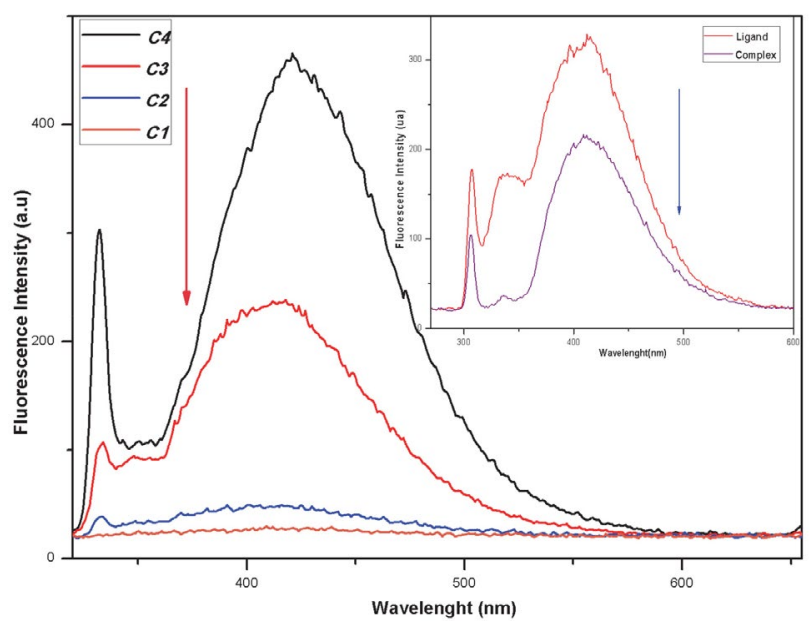

Figure 4. Fluorescence spectra of the complex (recorded in DMSO at $\left.\lambda_{\mathrm{ex}}=330 \mathrm{~nm}\right)$ at different concentrations $c_{1}=0.7 \cdot 10^{-4} \mathrm{M}, c_{2}=1.6$ $\cdot 10^{-5} \mathrm{M}, c_{3}=0.26 \cdot 10^{-5} \mathrm{M}, c_{4}=0.4 \cdot 10^{-6} \mathrm{M}$. The inset shows the spectra of complex and ligand (in DMSO at $\lambda_{\mathrm{ex}}=303 \mathrm{~nm}$ ) at concentration $1.6 \cdot 10^{-5} \mathrm{M}$. 
balt(II) ions. This effect has been observed in other cobalt(II) complexes. ${ }^{21}$ This phenomenon is known as fluorescence quenching. The comparison of the fluorescence spectra of the coordinated complex and uncoordinated coumarin (Fig. 4), recorded in the same solvent (DMSO) at concentration of $1.6 \cdot 10^{-5} \mathrm{M}$ and an excitation at 303 $\mathrm{nm}$ reveals a significant decrease in emission intensity and a slight hypsochromic shift of the complex. Indeed, there seems to be a transfer of intramolecular photoinduced electrons (PeT) from coumarin to the cobalt(II) cation. The photoluminescence properties of the cobalt complex result mainly from the coumarin ligand. During excitation, an electron transfer takes place from the coumarin fluorophore excited at the LUMO energy level of the cobalt(II) complex, which leads to the quenching of the fluorescence. The decrease in the fluorescence intensity also indicates that the $\mathrm{Co}$ (II) ions have a quality of fluorescent quenching. The results of our study are consistent with works reports of Singh et al. ${ }^{35}$

\section{4. Structural Study}

In the asymmetric unit of the crystal structure (Fig. $5)$, the $\mathrm{Co}$ (II) cation is coordinated by two $\mathrm{O}$ atoms $\left(\mathrm{O}_{1}\right.$, $\mathrm{O}_{2}$ ) and two $\mathrm{N}$ atoms (N4, N5). The octahedral environment of cobalt(II) consists of 3-acetyl-2-oxo-2H-chromen4-olato in equatorial sites in trans configuration and two pyridine molecules occupying the axial sites. The cobalt(II) atom exhibits an axially elongated octahedral $\mathrm{CoN}_{2} \mathrm{O}_{4} \mathrm{CO}-$ ordination geometry. Compared to the other crystal structures in the literature (Table 2) ${ }^{36}$, the $\mathrm{Co}-\mathrm{O}$ and $\mathrm{Co}-\mathrm{N}$ distances as well as the $\mathrm{O}-\mathrm{Co}-\mathrm{O}, \mathrm{O}-\mathrm{Co}-\mathrm{N}$ and $\mathrm{N}-\mathrm{Co}-\mathrm{N}$
Table 2. Selected bond length $(\AA)$ and bond angle $\left(^{\circ}\right)$ for complex

\begin{tabular}{lccc}
\hline Distance & $(\AA)$ & Angle & $\left(^{\circ}\right)$ \\
\hline Co1-O1 & $2.0562(10)$ & O1-Co1-O1 & $176.57(4)$ \\
Co1-O2 & $2.0407(11)$ & O1-Co1-O2 & $84.42(4)$ \\
Co1-N4 & $2.1596(16)$ & O1-Co1-O2 & $95.59(4)$ \\
Co1-N5 & $2.1585(16)$ & O2-Co1-O2 & $179.60(4)$ \\
O1-C4 & $1.2536(18)$ & N5-Co1-O1 & $88.28(4)$ \\
O2-C12 & $1.2610(17)$ & N4-Co1-O2 & $89.80(4)$ \\
N4-C18 & $1.3477(14)$ & N5-Co1-O2 & $90.20(4)$ \\
N5-C11 & $1.3441(15)$ & N4-Co1-O1 & $91.72(4)$ \\
\hline
\end{tabular}

Symmetry code: (i) $-x, y, 1 / 2-z$

angles are considered as the expected values of a cobalt(II) complex coordinated by four oxygen atoms in the equatorial plane and two nitrogen atoms in axial positions.

However, the angle between the equatorial plane (Co1-O1-O2) and the coumarin ligand $(\mathrm{O} 1-\mathrm{O} 2-\mathrm{C} 12)$ is $2.67^{\circ}$ which is smaller compared to the previously published compounds. ${ }^{21}$ In addition, the angle between the two planes of pyridine in the axial position, plane $1(\mathrm{C} 15 /$ $\left.\mathrm{C} 11 / \mathrm{N} 5 / \mathrm{C} 11^{\mathrm{i}} / \mathrm{C} 15^{\mathrm{i}} / \mathrm{C} 19\right)$ and plane $2\left(\mathrm{C} 18 / \mathrm{N} 4 / \mathrm{C} 18^{\mathrm{i}} / \mathrm{C} 17 /\right.$ $\left.\mathrm{C} 13 / \mathrm{C} 17^{\mathrm{i}}\right)$ with symmetry code: (ii) $(-x,-y,-z)$ is $53.81^{\circ}$. In the packing of crystal lattice, all the complex molecules are connected by an extensive network of hydrogen bonds (Table 3 ) and by interactions of type $\mathrm{C}-\mathrm{H} \cdots \pi$ and $\pi-\pi$. In fact, the intermolecular bond between the coumarin lactone group and the pyridine $\mathrm{C} 15-\mathrm{H} 1 \mathrm{c} 15 \ldots \mathrm{O} 4, \mathrm{C} 18-$ $\mathrm{H} 1 \mathrm{c} 18$... O 4 and C19-H1c19 .. O 3 creates a network of interactions of type $\mathrm{C}-\mathrm{H} \cdots \pi$ which can be seen in the packing diagram where the complexes are connected in chains parallel to the axis [001] (Fig. 6).

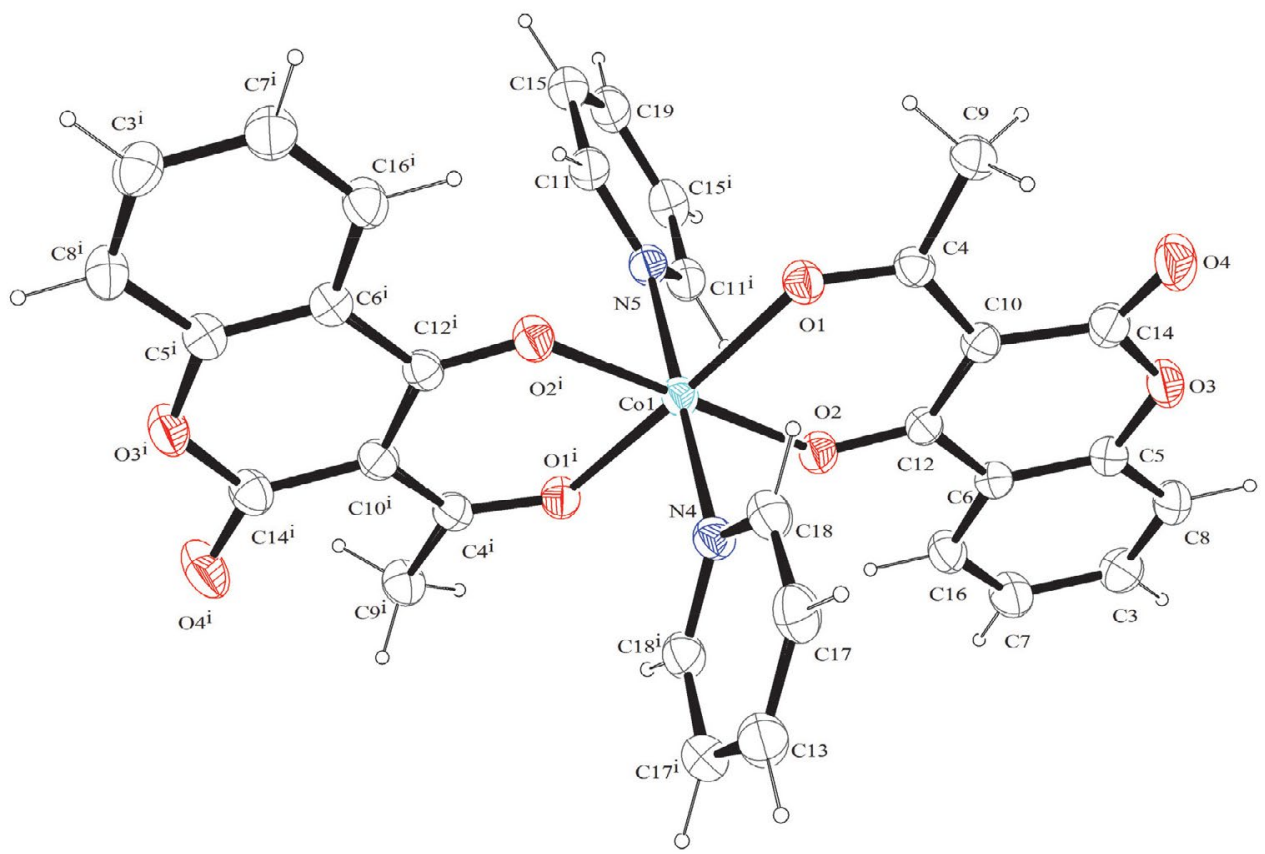

Figure 5. A perspective view of complex showing the atom-labelling scheme and displacement ellipsoids at the 50\% probability level, symmetry code: (i) $-x, y, 1 / 2-z$. 
Table 3. Hydrogen-bond geometry $\left(\AA{ }^{\circ}{ }^{\circ}\right)$ for complex

\begin{tabular}{lcccc}
\hline $\boldsymbol{D}-\mathbf{H} \boldsymbol{\cdots} \boldsymbol{A}$ & $\boldsymbol{D}-\mathbf{H}$ & $\mathbf{H} \boldsymbol{\cdots} \boldsymbol{A}$ & $\boldsymbol{D} \boldsymbol{\cdots} \boldsymbol{A}$ & $\boldsymbol{D}-\mathbf{H} \boldsymbol{\cdots} \boldsymbol{A}$ \\
\hline $\mathrm{C} 15-\mathrm{H} 1 c 15 \cdots \mathrm{O}^{\text {iv }}$ & 0.96 & 2.67 & $3.3905(19)$ & 132.34 \\
$\mathrm{C} 18-\mathrm{H} 1 c 18 \cdots 4^{\text {v }}$ & 0.96 & 2.44 & $3.1600(15)$ & 132.04 \\
$\mathrm{C} 19-\mathrm{H} 1 c 19 \cdots \mathrm{O}^{\text {iv }}$ & 0.96 & 2.66 & $3.2105(14)$ & 116.53 \\
\hline
\end{tabular}

Symmetry codes: (iv) $1 / 2+x, 1 / 2+y, z$; (v) $-1 / 2-x, 1 / 2-y,-z$.

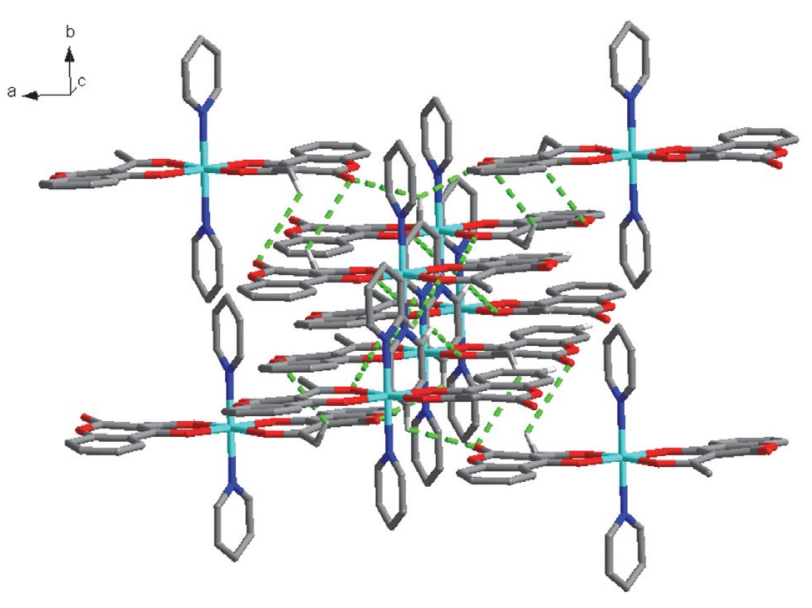

Figure 6. Crystal packing of complex showing the formation of a chain along [001], showing the intermolecular $\mathrm{C}-\mathrm{H} \cdots \mathrm{O}$ hydrogen bonds as thin green lines. Hydrogen atoms not involve in hydrogen bonding has been omitted for the sake of clarity.

These hydrogen bonds also connect the complexes in parallel layers to the $a$-axis. In the plane (110), we can also find layers that are weakly connected by offset $\pi-\pi$ interactions between coumarin ligands (Fig. 7).The benzene ring and the coumarinic lactone ring are in contact with the neighboring molecule via $\pi$-forces at the symmetry code (iii: $-1 / 2-x, 1 / 2-y, 1-z$ ) with intercentroid separations of 3.9533 (9) $\AA\left(\mathrm{Cg} 3 \cdots \mathrm{Cg} 6^{\mathrm{iii}}\right)$ and 3.6177 (10) $\AA$ (Cg6 … Cg6 $\left.6^{\mathrm{iii}}\right)$.

\section{5. Hirshfeld Surface Analysis}

The Hirshfeld surfaces were used for exploring intermolecular interactions in the studied crystal. ${ }^{37,38}$ The molecular Hirshfeld surfaces calculations were performed using the CrystalExplorer 3.1 program,${ }^{39}$ which accepts a structure input file in the CIF format. The Hirshfeld surfaces of the title compound are illustrated in Fig.8. This figure is showing surfaces that have been mapped over $d_{\text {norm }}$ (normalized contact distance) (Fig. $8(1)$ ), shape index (Fig. 8 (2)), curvedness (Fig. 8 (3)) and $d_{\mathrm{e}}$ (distance from a point on the surface to the nearest nucleus outside the surface) (Fig. 8 (4)). The Hirshfeld surfaces of cobalt(II) complex were generated using a standard (high) surface resolution with $3 \mathrm{D} d_{\text {norm }}$ surfaces mapped to a ranges -0.1829 to 1.0550 . The $d_{\text {norm }}$ mapping indicates that strong hydrogen bond interactions, such as $\mathrm{C}-\mathrm{H} \cdots \mathrm{O}$ hydrogen bonding between the oxygen of the lactone group and the pyridine appear as a primary interaction between the complex's molecules, seen as a bright red zone in the Hirshfeld surfaces (Fig. 8 (1)).

The size and shape of the Hirshfeld surface allow the qualitative and quantitative study and visualization of intermolecular close contacts in molecular crystals. The shape index and the curvature were used to identify packaging modes (planar stacking arrangements). In fact, the presence of $\pi \cdots \pi$ stack is evident as a flat region down on both sides of the molecules and is clearly visible on the curve surface. The pattern of the red and blue triangles on

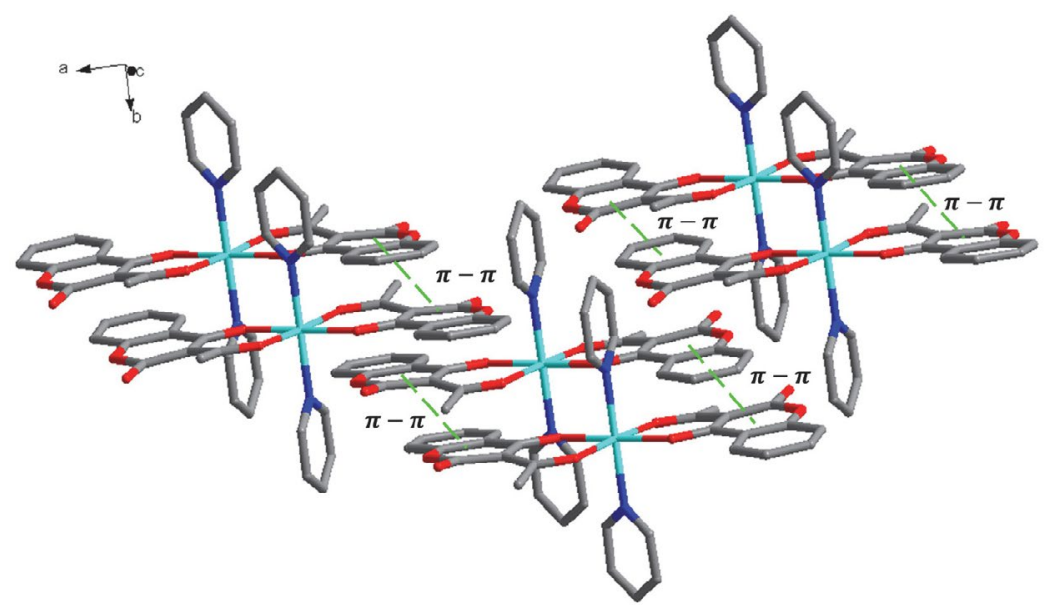

Figure 7. Crystal packing of complex showing a weak offset $\pi-\pi$ stacking interactions between coumarin ligands in (110) plane. The green dotted line represents $\pi-\pi$ stacking interactions. Hydrogen atoms have been omitted for clarity. 
$1-$

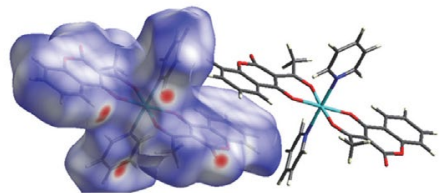

2-

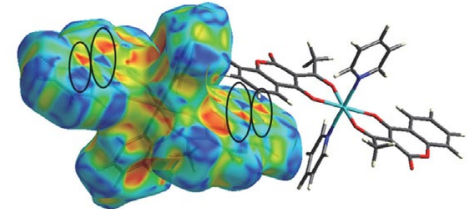

$3-$

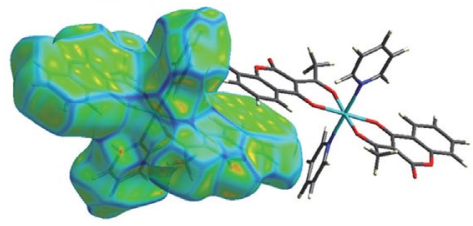

4-

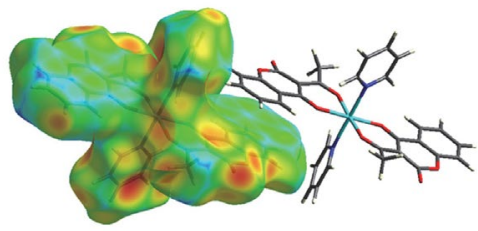

Figure 8. Hirshfeld surfaces of complex: (1) 3D $d_{\text {norm }}$ surface, (2) surface index, (3) curvedness, (4) $d_{\mathrm{e}}$.

the area of the shape index surface (Fig. 8 (2)) is characteristic of the $\pi \cdots \pi$ stacking. The blue triangles exhibit the convex regions due to the carbon atoms of the molecule inside the surface, while the red triangles represent the concave regions because of the carbon atoms of the stacked molecule $\pi$ above. ${ }^{40,41}$ The $\mathrm{C}-\mathrm{H} \cdots \pi$ contact in the crystal shows a bright-orange spots on the $d_{\mathrm{e}}$ surface (Fig. 8 (4)), ${ }^{38}$ directly above the center of the $\mathrm{C}=\mathrm{C}$ bonds and generates a distinct pattern of a pair of wings in the two-dimensional fingerprint plot (Fig. 9), it will become obvious that this is a characteristic feature of all $\mathrm{C}-\mathrm{H} \cdots \pi$ interactions.

The 2D fingerprint plots are deconstructed to highlight particular atom pair contacts. This allows the separation of the contributions of different types of overlapping interaction in the complete fingerprint. The analysis of $2 \mathrm{D}$ fingerprint plots for the title compound (Fig. 9) confirm that intermolecular $\mathrm{H} \cdots \mathrm{H}, \mathrm{C} \cdots \mathrm{H}$ and $\mathrm{H} \cdots \mathrm{O}$ interactions are well dominated and are in complement to the Hirshfeld surface. The first main interaction of type $\mathrm{H}$... $\mathrm{H}$ were represented by the largest region in the fingerprint plot with contribution $38.2 \%$. A second main interaction of type $\mathrm{C} \cdots \mathrm{H}$ is due to hydrogen bonds $\mathrm{C} 8 \cdots \mathrm{H} 1 \mathrm{c} 17-$ $\mathrm{C} 17$, and appears at the top left of the plot in the form of the characteristic wings with a contribution of $30.6 \%$, these can also be identified by $\mathrm{C}-\mathrm{H} \cdots \pi$ type interactions. This deduction is compatible with the qualitative $d_{\mathrm{e}}$ surface analysis. A third principal interaction of type $\mathrm{H} \cdots \mathrm{O}$ is manifested in the molecular structure by the $\mathrm{C} 15-\mathrm{H} 1 \mathrm{c} 15$ ‥ O 4 , C18-H1c18 … O 4 and $\mathrm{C} 19-\mathrm{H} 1 \mathrm{c19}$... O3 hydrogen bonds between axial pyridine and coumarin plane.
This type of interaction is presented as two sharp points pointing to the lower left of the plot which contributes $22.6 \%$ of the total. The interactions $\mathrm{C} \cdots \mathrm{C}$ exist in the $2 \mathrm{D}$ plot with a low contribution of $5.9 \%$. This contact corresponds to the parallel $\pi \cdots \pi$ stacks between the coumarin cycles. It's compatible with the surfaces of the shape index and the curvature.

a)

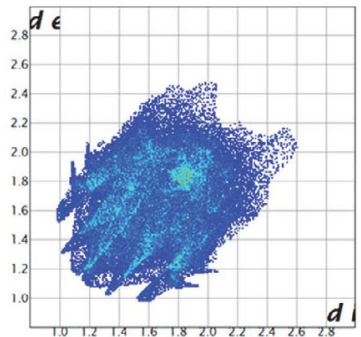

b)
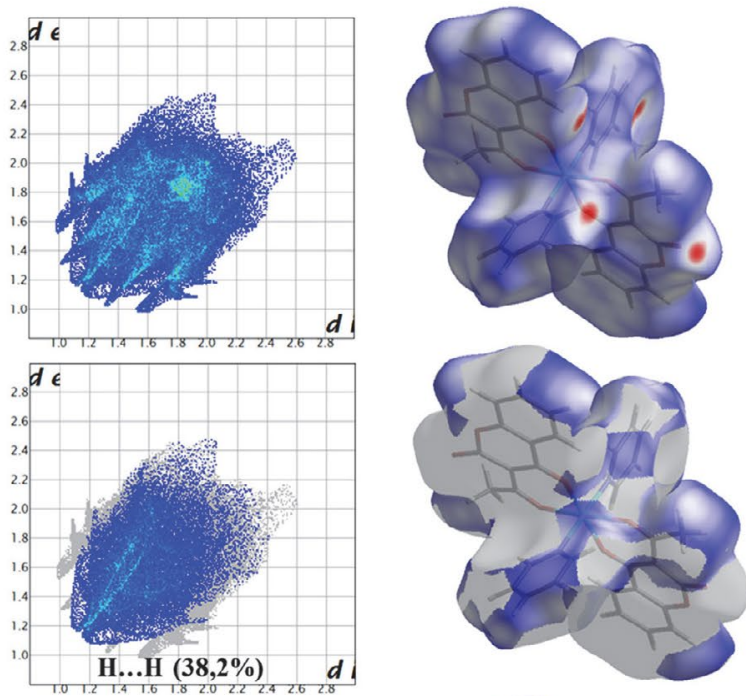

c)
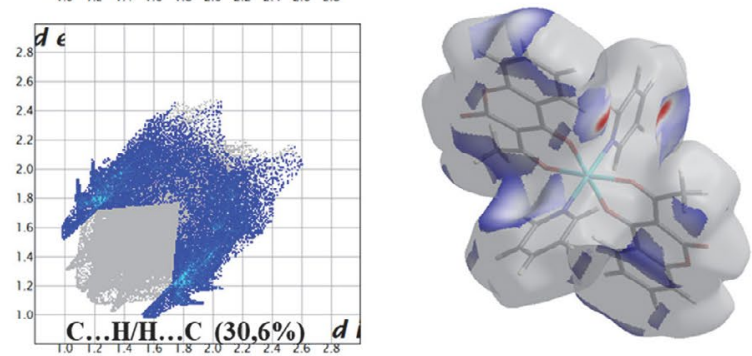

d)

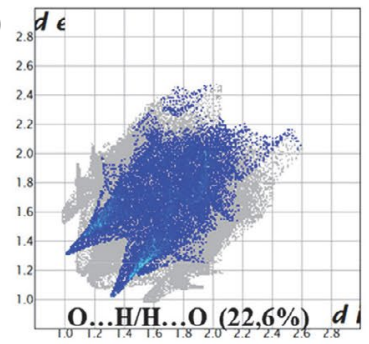

e)
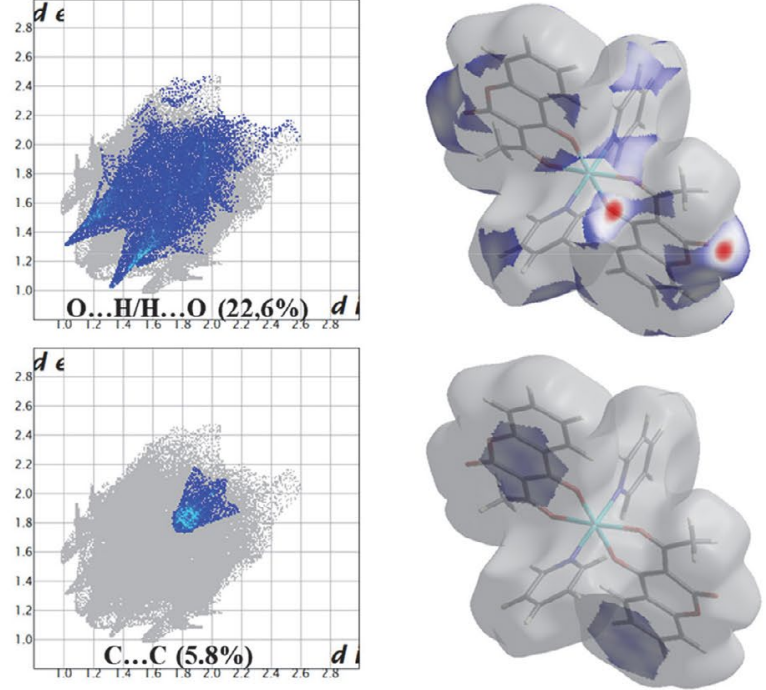

Figure 9. Two-dimensional fingerprint plots of the complex showing percentages of contacts contributing to the total Hirshfeld surface area of the molecule: (a) all interactions, and delineated into (b) $\mathrm{H} \cdots \mathrm{H},(\mathbf{c}) \mathrm{C} \cdots \mathrm{H} / \mathrm{H} \cdots \mathrm{C}$, (d) $\mathrm{O} \cdots \mathrm{H} / \mathrm{H} \cdots \mathrm{O}$ and (e) $\mathrm{C} \cdots \mathrm{C}$ interactions. 


\section{6. Antioxidant Activity}

The antiradical activity of the extracts is determined by the method of reduction of the free radical of DPPH (1,1-diphenyl-2-picrylhydrazyl). ${ }^{42}$ The DPPH radical is a stable organic free radical with an adsorption band at 515$518 \mathrm{~nm}$. The free radical scavenging mechanism is the transfer of the hydrogen atom from the test compound to $\mathrm{DPPH}$, which is transformed into a stable molecule DPPHH. ${ }^{43}$ The ability to reduce the DPPH radicals was determined by the decrease in its absorbance at $515 \mathrm{~nm}$ induced by antioxidants. The $\mathrm{IC}_{50}$ (scavenging concentration $50 \%$ ) allowing calculate the extract concentration needed to trap $50 \%$ of the DPPH radicals. It is determined graphically by linear regression. The graph was plotted with percent scavenging effects (\% IDPPH) according to concentration $(\mu \mathrm{mol} / \mathrm{L})$ (Fig. 10). The metal complex showed good activities as a radical scavenger with $\mathrm{IC}_{50}=0.0195 \mu \mathrm{mol} / \mathrm{L}$. A lower $\mathrm{IC}_{50}$ value indicates greater antioxidant activity, compared to ascorbic acid (vitamin C) as a reference that has an $\mathrm{IC}_{50}$ value of $21 \mu \mathrm{mol} / \mathrm{L},{ }^{44}$ it is considered a good free radical trapper. In addition, it possesses significant antioxidant activity relative to its coumarin ligand, ${ }^{21}$ and other similar cobalt(II) complexes. It is difficult to draw general conclusions about antioxidant structure-activity relationships with the limited number of antioxidant molecules. It may

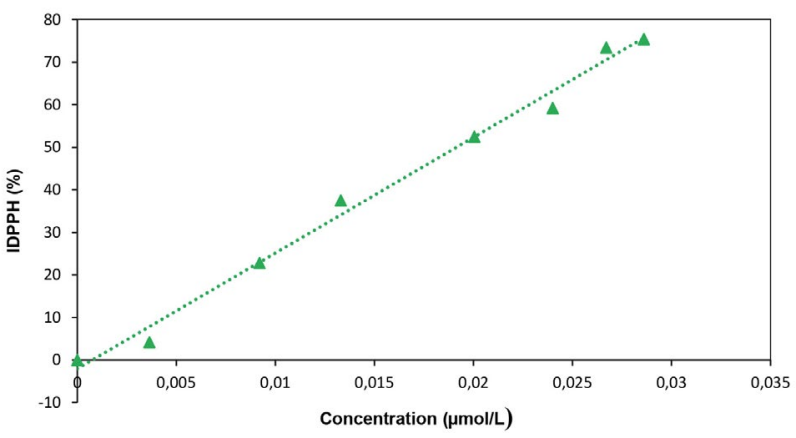

Figure 10. DPPH inhibition percentage curves of the coumarin complex.

be suggested that metal ions significantly change the chemical properties of coumarin ligand. The complexation with the transition metal was carried out via the carboxylate and phenol groups of the two ligands of coumarin in equatorial positions, this can improve the antiradical activity. ${ }^{45}$

\section{7. Antimicrobial Activity}

The antimicrobial activities of ligand and complex were screened against six Gram-negative bacteria: Escherichia coli, Pseudomonas aeruginosa, Salmonella typhimurium, Vibrio alginolyticus, Pseudomonas fluorescens and Vib-

Table 4. Antimicrobial activities of the synthesized coumarin ligand and complex

\begin{tabular}{lcccccccc}
\hline Microorganisms & E. coli & P. aeruginosa & S. typhimurium & V.alginolyticus & P. fluorescens & C. albicans V. anguillarum & S. aureus \\
\hline $\begin{array}{l}\text { Compound } \\
(2 \mathrm{mg} / \mathrm{mL})\end{array}$ & \multicolumn{7}{c}{ INHIBITION ZONES (mm) } \\
\hline Coumarin ligand & 11.33 & 11 & 11.66 & 11 & 11.33 & 12.66 & 10.33 & 11 \\
Complex & 11.66 & 8 & 9.33 & 13.33 & 8.33 & 8.66 & 12 & 8.66 \\
Control (DMSO) & 0 & 0 & 0 & 0 & 0 & 0 & 0 & 0 \\
\hline
\end{tabular}

All data are the averages of the measurements in triplicate

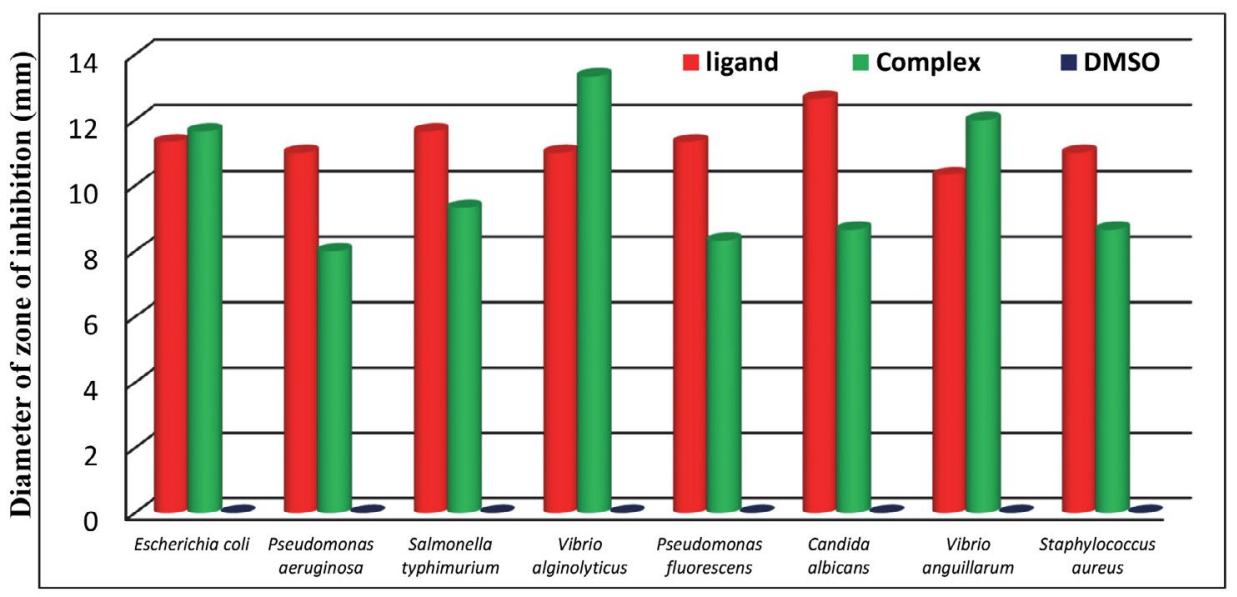

Microorganismes

Figure 11. Antibacterial activity spectrum of the complex. 
rio anguillarum and a Gram-positive bacterium: Staphylococcus aureus and against a fungus, ie Candida albicans, to evaluate their potential as an antimicrobial agent.

The antimicrobial activities of the complex and its coumarin ligand under test against different strains of bacteria are shown in Table 4 and Figure 11. The most sensitive microorganisms to the Co complex were Escherichia coli, Vibrio alginolyticus and Vibrio anguillarum (gram negative) with inhibition diameters of 11.66, 13.33 and 12 $\mathrm{mm}$, respectively. This complex also showed low activity against Pseudomonas aeruginosa, Salmonella typhimurium, Pseudomonas fluorescens, Candida albicans and Staphylococcus aureus. In contrast, the coumarin ligand 3-acetyl-4-hydroxycoumarin exhibits a broad antibacterial activity against all strains tested but was more active against Escherichia coli, Pseudomonas aeruginosa, Salmonella typhimurium, Pseudomonas fluorescens, Candida albicans and Staphylococcus aureus with inhibition diameters of $11.33,11,11.66,12.66,11.33$, and $11 \mathrm{~mm}$, respectively. This relatively high antibacterial activity of uncoordinated coumarin may be due to its flat molecular structure that contributes to penetration across the membrane or bacterial cell wall. ${ }^{46}$ It is clear that the zones of inhibition may be larger or weak for metal chelates than for the coumarin ligand for certain microorganisms. In addition, the antibacterial actions of coumarin ligand can be significantly improved upon chelation with cobalt(II) ions. ${ }^{47}$ In particular cases, the increase in antimicrobial activity is due to the faster diffusion of metal complexes as a whole across the cell membrane or to the combined activity of the metal and the ligand. ${ }^{48}$

The minimum inhibitory concentration (MIC) was determined by the micro-dilution method according to the standard reference method for bacteria. ${ }^{49}$ Various concentrations of metal complex solutions $(62.5,125,250,500$ $\mu \mathrm{g} / \mathrm{mL}$, and $1 \mathrm{mg} / \mathrm{mL}$ ) were obtained by dissolving the compound in DMSO (2\%) and then diluted to give serial two-fold dilutions. These solutions were added to each medium in the 96-well plates. The bacterial suspensions are added at the rate of $180 \mu \mathrm{L}$ in suspension of $10^{6}$ bacte$\mathrm{ria} / \mathrm{mL}$ to each well. The purpose of this method was to determine the exact concentration of the compound under study which will have an inhibitory effect on growth selected microorganisms. This concentration was considered as minimal inhibition concentration (MIC). The MIC values was determined against Escherichia coli, Vibrio algi-

Table 5. Minimum Inhibitory Concentration assay of metal complex against bacterial pathogens

\begin{tabular}{lccc}
\hline Microorganisms & $\begin{array}{c}\text { Escherichia } \\
\text { coli }\end{array}$ & $\begin{array}{c}\text { Vibrio } \\
\text { alginolyticus }\end{array}$ & $\begin{array}{c}\text { Vibrio } \\
\text { anguillarum }\end{array}$ \\
\hline Complex & \multicolumn{3}{c}{ MIC (mg/mL) } \\
Control (DMSO) & 0.250 & 0.125 & 0.125 \\
\hline
\end{tabular}

nolyticus and Vibrio anguillarum bacteria which have an inhibition diameter greater than $10 \mathrm{~mm}$. As a negative control, DMSO did not affect the growth of bacterial strains at the concentrations used in this study. Values of MIC of complex are shown in Table 5. It should be noted that the cobalt(II) complex exhibited a good MIC result against Gram negative bacteria.

\section{Conclusion}

In this paper, a novel Co(II) complex trans-dipyridinbis(3-acetyl-2-oxo-2H-chromen-4-olato)cobalt(II) was synthesized and characterized by different spectroscopic techniques. The bonding of ligand to metal ion is confirmed by spectral studies (UV-Vis, IR, and fluorescence). The IR spectral analysis shows a decrease in the frequency of the stretch band of the $\mathrm{C}=\mathrm{O}$ acetyl group with respect to the coumarin which may be due to the donor-acceptor interaction of this group with the cobalt(II) cation. The UV-Vis spectral studies suggested an octahedral geometry for the Co(II) complex. The metal-ligand coordination causes a decrease in the fluorescence intensity (the fluorescence quenching) and an offset of the emission wavelength. The crystal structure of the Co complex was studied by single-crystal X-ray diffraction; the cobalt(II) atom exhibits an axially elongated octahedral $\mathrm{CoN}_{2} \mathrm{O}_{4}$ coordination geometry. In the packing of crystal lattice, all the complex molecules are connected by an extensive network of $\mathrm{C}-\mathrm{H} \cdots \mathrm{O}$ hydrogen bonds and by interactions of type $\mathrm{C}-\mathrm{H} \cdots \pi$ and $\pi-\pi$. The molecular Hirshfeld surface and 2D fingerprint plots were used for quantitative mapping out of molecular interactions, revealing that close contacts are dominated by $\mathrm{H} \cdots \mathrm{H}, \mathrm{C} \cdots$ $\mathrm{C}$ and $\mathrm{C} \cdots \mathrm{H}$ interactions, these relatively weak contacts have clear signatures in the fingerprint plots. The new coumarin complex reveal potentially important antioxidant activity against free radicals DPPH compared to the coumarin derivative ligand and vitamin C. The antimicrobial studies suggested that the coumarin derivative ligand is biologically active and its metal complex exhibits significantly enhanced antimicrobial activity against some microbial strains in comparison to the free ligand. Thus, this new cobalt(II) complex can be used further in the pharmaceutical industry, as an antioxidant and antimicrobial agent, after testing its toxicity to humans.

\section{Supplementary Material}

CCDC reference number 1891314 for the cobalt complex contain the supplementary crystallographic data for this paper. These data can be obtained free of charge at www.ccdc.cam.ac.uk, or from Cambridge Crystallographic Data Center, 12, Union Road, Cambridge CB2 1EZ, UK; Fax: +44 1223336 033; e-mail: deposit@ccdc.cam.ac.uk. 


\section{Acknowledgements}

Financial support from the Ministry of Higher Education and Scientific Research of Tunisia is gratefully acknowledged. The authors gratefully also acknowledge the ICDD for financial support (Grant number: 09-04). The crystallographic part was supported by the project LO1603 under the Ministry of Education, Youth and Sports National sustainability program I of Czech Republic, using instruments of the ASTRA laboratory established within the Operation program Prague Competitiveness - project CZ.2.16/3.1.00/24510.

\section{References}

1. D. Egan, R. O’Kennedy, E. Moran, D. Cox, E. Prosser, R. D. Thornes, Drug Metab. Rev. 1990, 22, 503-529.

DOI: $10.3109 / 03602539008991449$

2. H. Xiongfeng, L. Lvye, X. Qun, J. Rohrer, Thermo Fisher Scientific Application Note. 2016, pp. 1128.

3. L. Hongqi, C. Li, C. Zhen, Adv. Chem. Sensors. 2012, pp. 121150. DOI: $10.5772 / 33157$

4. E. Guardado Yordi, M.J. Matos, A. Pérez-Martínez, C. Tornes, L. Santana, E. Molina Pérez, E. Uriarte, Food Funct. 2017, 8, 2958-2966. DOI:10.1039/C7FO00402H

5. P. K. Jain, H. Joshi, J. Appl. Pharm. Sci. 2012, 2, 236-240. DOI:10.7324/JAPS.2012.2643

6. Y. Bansal, P. Sethi, G. Bansal, Med. Chem. Res. 2013, 22, 30493060. DOI:10.1007/s00044-012-0321-6

7. D. R. Vianna, L. Hamerski, F. Figueiró, A. Bernardi, L.C. Visentin, Eur. J. Med. Chem. 2012, 57, 268-274.

DOI:10.1016/j.ejmech.2012.09.007

8. K. Rohini, P.S. Srikumar, J. Biofertilizers Biopestic. 2014, 5, 5-7. DOI:10.4172/2157-7544.1000130

9. I. P. Kostova, I. I. Manolov, I. N. Nicolova, N. D, Danchev, Farmaco. 2001, 56, 707-713.

DOI:10.1016/S0014-827X(01)01109-0

10. D. N. Kanthecha, D. B. Raval, V. R. Thakkar, M. N. Patel, Acta Chim. Slov. 2018, 65, 333-343. DOI:10.17344/acsi.2017.4018

11. S. J. S. Franchi, R. A. de Souza, A. E. Mauro, I. Z. Carlos, L. C. de Abreu Ribeiro, F. V. Rocha, A. V. de Godoy-Netto. Acta Chim. Slov, 2018, 65, 547-553. DOI:10.17344/acsi.2017.4112

12. I. Sheikhshoaie, A. Badiei, M. Ghazizadeh, Der Chem. Sin. 2012, 3, 24-28.

13. A. S. Munde, V. A. Shelke, S. M. Jadhav, A. S. Kirdan, S. R. Vaidya, S. G. Shankarwar, T. K. Chondhekar, Adv. Appl. Sci. Res. 2012, 3, 175-182.

14. D. Lai Peng, N. Sun, Acta Chim. Slov. 2018, 65, 895-901. DOI:10.17344/acsi.2018.4543

15. I. Ketata, T. Bouzaiene, T. Ben Ayed, R. Ben Hassen, Mediterr. J. Chem. 2014, 3, 767-779.

DOI:10.13171/mjc.3.1.2014.08.04.14

16. L. W. Xue, H. J Zhang, P. P. Wang, Acta Chim. Slov. 2019, 66, 190-195. DOI:10.17344/acsi.2018.4773

17. A. Karaliota, O. Kretsi, C. Tzougraki, J. Inorg. Biochem. 2001, 84, 33-37. DOI:10.1016/S0162-0134(00)00214-2
18. G. Kokotos, V. Theodorou, C. Tzougraki, D. L. D. Deforce, E. G. Van Den Eeckhout, Bioorganic Med. Chem. Lett. 1997, 7, 2165-2168. DOI:10.1016/S0960-894X(97)00384-3

19. C. R. Munteanu, K. Suntharalingam, Dalton Trans. 2015, 1-19. DOI:10.1039/C5DT02101D

20. N. Shahabadi, S. Kashanian, F. Darabi, Eur. J. Med. Chem. 2010, 45, 4239-4245. DOI:10.1016/j.ejmech.2010.06.020

21. L. Bejaoui, J. Rohlicek, R. Ben Hassen, J. Mol. Struct. 2018, 1173, 574 -582. DOI:10.1016/j.molstruc.2018.07.017

22. A. Ghouili, R. Ben Hassen, Acta Crystallogr. Sect. E Struct. Reports Online. 2011, 67, 6-13. DOI: $10.1107 / S 160053681102980$

23. A. Ghouili, M. Dusek, V. Petricek, T. Ben Ayed, R. Ben Hassen, J. Phys. Chem. Solids. 2014, 75, 188-193.

DOI:10.1016/j.jpcs.2013.09.011

24. A. Brahmia, T. Ben Ayed, R. Ben Hassen, Acta Crystallogr. Sect. E Struct. Reports Online. 2013, 69, 1296. DOI:10.1107/S160053681301934X

25. J. Rohlíček, I. Ketata, T. Ben Ayed, R. Ben Hassen, J. Mol. Struct. 2013, 1051, 280-284.

DOI:10.1016/j.molstruc.2013.08.031

26. I. Ketata, L. Mechi, T. Ben Ayed, M. Dusek, V. Petricek, R. Ben Hassen, Open J. Inorg. Chem. 2012, 2, 33-39.

DOI:10.4236/ojic.2012.22006

27. A. Ghouili, A. Brahmia, R. Ben Hassen, Acta Crystallogr. Sect. C. 2015. 71, 873-877. DOI:10.1107/S2053229615016083

28. CrysAlis $P R O$ version1.171.38.43, Rigaku Oxford Diffraction: Yarnton, UK, 2015.

29. L. Palatinus, G. Chapuis, J. Appl. Crystallogr. 2007, 40, 786790. DOI:10.1107/S0021889807029238

30. V. Petricek, M. Dusek, L. Palatinus, Jana. The crystallographic computing system, Institute of Physics. Praha, Czech Republic, 2006.

31. K. Brandenburg, H. Putz, "DIAMOND Version 3", Crystal Impact GbR, Postfach 1251, D-53002 Bonn, Germany, 2005.

32. L. J. Farrugia, J. Appl. Cryst. 2012, 45, 849-854. DOI: $10.1107 / S 0021889812029111$

33. A. Ismail, L. Ktari, A. Boudabbous, M. El Bour, Bull. Inst. Natn. Scien. Tech. Mer de Salammbô. 2010, 37, 127-132.

34. A. Bernalte-Garcia, F. J. Garcia-Barros, F. J. Higes-Rolando, F. Luna-Giles, Bioinorg. Chem. Appl. 2004, 2, 307-316. DOI: $10.1155 / S 1565363304000184$

35. K. Singh, Y. Kumar, P. Puri, G. Singh, Bioinorg. Chem. Appl. 2012, 2012, 1-9. DOI:10.1155/2012/729708

36. R. Kirchmaier, E. Altinand, A. Lentz, Z. Krist. 2004, 219, 29-30.

37. M. A. Spackman, D. Jayatilaka, CrystEngComm. 2009, 11, 19-32. DOI:10.1039/B818330A

38. J. J. McKinnon, M. A. Spackman, A. S. Mitchell, Acta Crystallogr. Sect. B 2004, 60, 627-668.

DOI:10.1107/S0108768104020300

39. S. K. Wolff, D. J. Grimwood, J. J. McKinnon, D. Jayatilaka, M. A. Spackman, Crystal Explorer 3.1, University of Western Australia, Perth, Australia, 2012.

40. Y. H. Luo, G. G. Wu, S. L. Mao, B. W. Sun, Inorg. Chim. Acta 2013, 397, 1-9. DOI:10.1016/j.ica.2012.11.010 
41. I. Bennour, M. Haukka, F. Teixidor, C. Viñas, A. Kabadou, J. Organomet. Chem. 2017, 846, 74-80.

DOI:10.1016/j.jorganchem.2017.05.047

42. W. Brand-Williams, M. E. Cuvelier, C. Berset, Food Sci. Technol. 1995, 28, 25-30. DOI:10.1016/S0023-6438(95)80008-5

43. P. Molyneux, Songklanakarin J. Sci. Technol. 2004, 26, 211219.

44. Y. C. F. Ladoh, S. D. Dibong, M. A. Nyegue, T. R. P. Djembissi, N. B. Lenta, M. E. Mpondo, J. Yinyang, J. D. Wansi, J. Appl. Biosci. 2014, 84, 7636-7643. DOI:10.4314/jab.v84i1.9
45. M. Rajeshirke, R. Shah, P. Yadav, N. V. Purohit, Der Pharmacia Sinica. 2012, 3, 239-248.

46. O. Kayser, H. Kolodziej, Z. Naturforsch. 1999, 54c, 169-174. DOI:10.1515/znc-1999-3-405

47. N. K. Singh, M. S. Agrawal, R. C. Aggarwal, Synth. React. Inorg. Met. Chem. 1985, 15, 75-92.

DOI:10.1080/00945718508059368

48. N. Fahmi, R. V. Singh, Transit. Met. Chem. 1994, 19, 12-16. DOI:10.1007/BF00139327

49. V. Duraipandiyan, S. Ignacimuthu, J. Ethnopharmacol. 2009, 123, 494-498. DOI:10.1016/j.jep.2009.02.020

\section{Povzetek}

V etanolu smo sintetizirali nov kobaltov(II) kompleks trans-dipiridinbis(3-acetil-2-okso-2H-kromen-4-olato)kobalt(II). Koordinacijska sfera kobaltovega kationa je bila določena $\mathrm{z}$ monokristalno rentgensko difrakcijo in spektroskopskimi tehnikami (FT-IR, UV-Vis in fluorescenca). Hirshfeldova analiza površine kaže, da predstavljajo vodikove vezi, kot je $\mathrm{C}-\mathrm{H}$... O vodikova vez med kisikovim atomom laktonske skupine in piridinom, najpomembnejše interakcije med molekulami. Prisotnost $\pi-\pi$ interakcij je razvidna na podlagi indeksa oblike in ukrivljenosti. Analiza $2 \mathrm{D}$ diagramov potrjuje, da dominirajo intermolekularne $\mathrm{H} \cdots \mathrm{H}, \mathrm{C} \cdots \mathrm{H}$ in $\mathrm{H} \cdots \mathrm{O}$ interakcije, kar je v soglasju s Hirshfeldovo površino. Koordinacija kovina-ligand močno vpliva na intenziteto fluorescence in na zamik emisijske valovne dolžine. Kompleks smo testirali tudi na antimikrobno aktivnost $\mathrm{z}$ uporabo difuzijske metode na disku in kaže znatno aktivnost $\mathrm{v}$ primerjavi s kumarinom.

Except when otherwise noted, articles in this journal are published under the terms and conditions of the Creative Commons Attribution 4.0 International License 